the angular momentum (per unit mass) of the sun, referred to the centre of the system, is so much less than that of the planets; and (3) why the angular momentum (per unit mass) of a planet; such as Jupiter, referred to the centre of the planetary system, is so much less than that of its satellites.

K. E. Edgeworth.

Cherbury, Booterstown,

Co. Dublin. Dec. 24.

'NATURE, 152, 721 (1943).

\title{
A Case of Total Asymmetric Synthesis
}

WE have recently announced a successful synthesis of santonin $(I)^{1}$. We believed then that it was racemic. We have since found it to be optically active. The synthetic specimen has a rotation of $[\alpha] D=-150$ add m.p. $171^{\circ}$. Sodium santoniate prepared from this sample was fractionally precipitated as the strychnine salt. This salt on decomposition gave santonin with $[\alpha] D=-172$ identical with the rotation of natural santonin. The filtrates gave another product with identical m.p. $\left(171^{\circ}\right)$ and rotation $[\alpha]_{D}=-108$, which was not changed on further fractional precipitation by strychnine or quinine hydrochloride, but in no case was a dextro-rotatory product obtained. So far as we are aware, this is the first total asymmetric synthesis, apart from asymmetric synthesis carried out in the presence of polarized light, etc.

We have also prepared compounds II, III, IV and $V$. It has been found that asymmetric synthesis occurred only in those compounds (I, IV and V) which had an angular methyl group. The others were racemic and could be resolved into $d$ - and $l$-forms through their strychnine salts.<smiles>CCC1C(=O)OCC2CCC3(C)C=CC(=O)C(C)=C3CC21</smiles>

I<smiles>[CH]C1C(=O)OC2C3=CC(=O)C=CC3CCC12</smiles>

II $d$-form $[a] D=+112$ $l$-form $[a] D=-112$

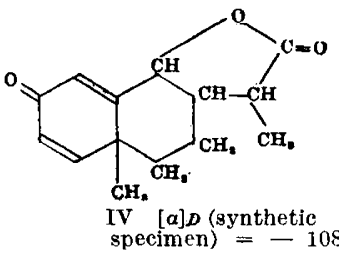<smiles>CC1CC2=CC(=O)C=CC2(C)[C@H]1C</smiles>

$\mathrm{V}[\alpha] \boldsymbol{D}$ (synthetic specimen) $=-55 \cdot 65$

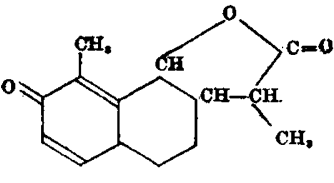

III $d$-form $[a] b=+158 \cdot 4$ $l$-form $[\alpha] D=-158 \cdot 3$

cyclohexanone or the corresponding derivative ap pears to be the stage at which the esymmetric synthesis occurs.

All rotations have been determined in chloroform solution at $28^{\circ} \mathrm{C}$.

Further work is in progress.

K. D. Paranjape.

N. L. Phalnikar.

B. V. BHIDE.

K. S. NARgund.

Maharaja Pratapsinh Chemical Laboratory, Sir Parashurambhau College,

Poona, 2.

Nov. 13.

${ }^{1}$ Current Science, 12, 153 (1943).

\section{Aerial Disinfection}

THE letter from workers at the National Institute of Medical Research ${ }^{1}$ was of interest to us, as we also find that lactic acid is an effective bactericidal aerosol, when the test organism is $C$. xerosis, emulsified in sterile saliva.

Bechhold ${ }^{2}$ long ago advocated the use of hydroxy and carboxylic acids as germicidal aerosols. We found cinnamic and benzoic acids (both constituents. of Peru balsam ${ }^{3}$ ) to be strong aerial bactericides, but acids, such as citric, fumaric, maleic, malic and phthalic tested recently proved relatively ineffective. On the other hand, maleie and phthalic anhydrides were found to be more active than their corresponding acids. In a concentration of $4 \mathrm{mgm} . / \mathrm{m}^{3}$. and a relative humidity of about 60 per cent, maleic anhydride generally sterilized the air of our test organism within five minutes; the durability of lethal effectiveness being good, a 15-minute old mist only allowing survival of some 5 per cent of the bacteria beyond the 5 -minute exposure time.

As regards the amount of germicide necessary to sterilize or nearly sterilize the air of our test organism within 5 minutes, it was found that of fifteen phenolic compounds examined, each required the vapour concentration to be of the order of 25 per cent saturation. Saturation at $20^{\circ} \mathrm{C}$. was calculated from the vapour pressures deduced from the formula of Clausius and Clapeyron (which can be expressed as log $p=$ $A+B / T$, where $A$ and $B$ are constants). Other substances, for example, mercuric chloride, propylene and diethyleno glycols, apparently asymmetric synthesis occurs by carrying out the synthesis of $V$ by the following reactions :<smiles>CCCCOCC1(CCC)CCCCC1=O</smiles>

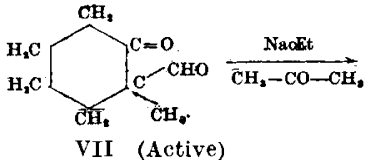

VII is an unstable liquid and cannot be purified by distillation, and also its solid derivative could not be prepared. However, the crude substance had an optical rotation $[\alpha]_{D}=-26 \cdot 22$. The corresponding methylated formyl derivative used in the synthesis of santonin could not be examined for optical activity as it was highly coloured. Methylation of the formyl require to be of an approximately similar concentration. Notable ex. ceptions are iodine and maleic anhydride (below 1 per cent), suggesting that the mechanism of the lethal effect here is different from that of<smiles>C[CH]CC1=CC(=O)C=CC1(CC)C(C)C</smiles>
the phenols. It will thus be understood that while we see no reason to alter our opinion ${ }^{4}$ regarding the fundamental importance of the vapour pressure of phenols in relation to activity on air-borne bacteria, it appears that this particular characteristic is not a reflexion of the activity of all groups of substances. Again, we do not consider water solubility an essential 